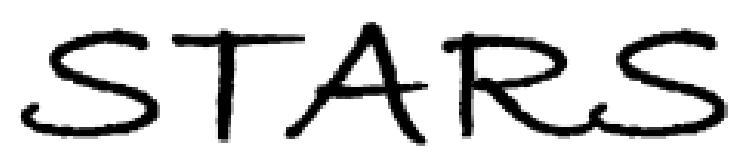

University of Central Florida

STARS

$11-1-2012$

\title{
Examining the RV Travelers' Camping Experience: A Social Media Approach
}

Jill Fjelstul

University of Central Florida, jill.fjelstul@ucf.edu

Youcheng Wang

University of Central Florida, Youcheng.Wang@ucf.edu

Part of the Hospitality Administration and Management Commons, and the Tourism and Travel Commons

Find similar works at: https://stars.library.ucf.edu/rosenscholar

University of Central Florida Libraries http://library.ucf.edu

This Paper is brought to you for free and open access by the Rosen College of Hospitality Management at STARS. It has been accepted for inclusion in Rosen Faculty Scholarship and Creative Works by an authorized administrator of STARS. For more information, please contact STARS@ucf.edu.

\section{Original Citation}

Fjelstul, J., Wang, Y.C., and Li, X. (2012). Examining the RV Travelers' Camping Experience: A Social Media Approach. Tourism Analysis. 17(4), 403-415.

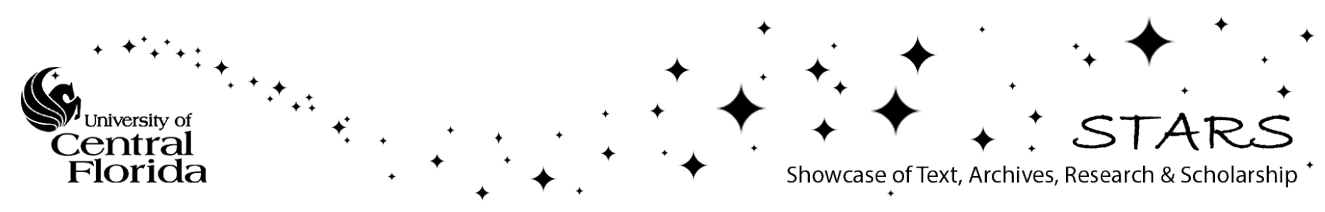




\title{
EXAMINING THE RV TRAVELERS' CAMPING EXPERIENCE: A SOCIAL MEDIA APPROACH
}

\author{
JILL FJELSTUL, YOUCHENG WANG, AND XU LI
}

Rosen College of Hospitality Management, University of Central Florida, Orlando, FL, USA

\begin{abstract}
The aim of this study was to analyze RV travelers' experience posted on campground online review websites. The study contributes to the relevant literature by understanding what influences the campground experience. Findings were categorized by six themes: campground attributes, campsite attributes, outdoor activities, surrounding area, campground policies, and staff. Findings also depicted major topic areas revealed in the reviewed postings. Implications were outlined for the campground owner/operator and future RV traveler as a result of this study.
\end{abstract}

Key words: RV traveler; Campground; Travel experience; Online reviews; Social media

Introduction

Recreation vehicle (RV) travel is gaining popularity. According to the Recreation Vehicle Industry Association (www.rvia.org), approximately 8.3 million American families own RVs, an increase of 15\% between 2001 and 2010. During the same period, American households grew only 10\%. In addition, one in six American households plans to purchase a RV in the future. People opt for RV travel due to its freedom, flexibility, and more personal control over where and when to go, how long to stay, and what activities to engage in (O'Brien, n.d.). Moreover, affordability is another driving factor. PKF Consulting (www. pkfc.com), an international travel and tourism research firm, has conducted longitudinal analyses on vacation cost and compared the cost of various typical family RV trips with other types of vacations. The results indicated that RV vacations cost less than a trip by personal car or airline coupled with hotels and rental cars, or taking a cruise or renting a condo. Therefore, the RV travel market is growing and attractive as more people buy their own RVs.

The flexibility of RVing offers travelers a wider range of options at the destination and/or along their travel route (Fodness \& Murray, 1997). The RV traveler has over 16,000 campgrounds (www. gorving.com) to choose from during their decisionmaking process. The campgrounds vary from primitive sites with minimal at-site convenience to luxury gated communities with clubhouse amenities. To market campgrounds and/or destinations and to assist the RV traveler in their decision 
making, business to consumer resources have been created (www.aaa.com; www.trailerlife.com; www. woodalls.com). RV travelers, however, are generally experienced travel consumers and more likely to plan trips based on their personal experience (Fodness \& Murray, 1999).

The emergence of Web 2.0 has fundamentally changed the way consumers search and use travel information (Ponting, 2009; Xiang \& Gretzel, 2010), thus influencing how RV travelers make their travel decisions. The participatory feature of the so-called social media websites enable people with common interest to interact with each other whenever and however they like. A vast pool of high-quality and relevant consumer-generated information, therefore, could be identified in various forms of social media websites such as blogs, virtual communities, user reviews, wikis, social network, etc. (O'Connor, 2008). On the one hand, consumers post their travel experience on these websites and tell each other interesting stories and helpful tips (Wang \& Fesenmaier, 2004; Xiang \& Gretzel, 2010). The collaboration between likeminded peers enriches and diffuses travel information through the Internet, having a great impact on travel decision making. On the other hand, potential travelers search travel information on social media websites. The information sharing and social interaction among members of an online social network provide potential travelers with a variety of benefits facilitating their decision making (Laing \& Crouch, 2009; Wang \& Fesenmaier, 2004; Yoo \& Gretzel, 2011). As a new form of word of mouth (WOM), the consumer-generated information is perceived independence from commercial entities and has gained much credibility in the eyes of consumers (Litvin, Goldsmith, \& Pan, 2008).

The purpose of this study was to analyze RV traveler experiences posted on campground online review websites. The study contributes to the relevant literature by understanding what influences the campground experience. Such knowledge will assist campground owners/operators in the marketing and management of their property as well as to potentially increase their market share of RV travelers. The analysis will also benefit the RV consumers in their future RV travel planning process and potential campground selection.
Literature Review

\section{Information Search in Travel Decision}

Information search is an important step in the consumer decision-making process. Engel, Blackwell, and Miniard (1993) defined information search as the motivated activation of knowledge stored in memory and/or the acquisition of information from the environment. The literature has also defined three main theoretical approaches regarding information search behaviors. The psychological and/or motivation approach focuses primarily on a person pushed by their personal internal forces and pulled by external forces of the destination (Cha, McCleary, \& Uysal, 1995; Shoemaker, 1994). The economics approach focuses on the expected costs and benefits of the potential information source. Lee and Cunningham (2001) found information search declines when the perceived cost of acquiring such information is high. The consumer information processing approach, according to Bieger and Laesser (2004), incorporates input variables and a phased decision-making process. The latter includes information acquisition, a process phase, and a consumption phase (Correia, 2002; Vogt \& Fesenmaier, 1998).

Information is the lifeblood of the travel industry due to the complexity of travel decision-making and the significant role information plays in the process (Wang \& Russo, 2007). First, the travel product is a combination of alternative transportation modes, accommodation and catering choices, and travel routes provided by different suppliers. Planning a trip, even the simplest one, involves choosing between a perplexing collection of options (O'Connor, 2008). A satisfactory trip is highly dependent on accurate and updated information. Second, the intangible nature of the travel product heightens the need for travel information. Unlike manufactured products, consumers are unable to try the travel product before purchase. High level of perceived risk is associated with consumption of travel product (O'Connor, 2008). As a result, consumers are hunting for vast amounts of information to help them make choices.

Tourism literature has explored the information search behavior of consumers. For example, Vogt and Fesenmaier (1998) found the information 
search process begins when a tourist is faced with a future decision. Crompton and Ankomah (1993) argued the magnitude of the search correlates with the perceived level of risk of the proposed destination. McCleary and Whitney (1994) concurred, stating consumers acquire information to reduce the uncertainty of their future activities. Moreover, Gursoy and McCleary (2004) developed an integrative model to better understand the impact of previous visits, involvement, intentional learning, familiarity, expertise, internal search, and the cost of external searches on a tourist's information search behavior. Fodness and Murray (1997) found information search for most tourism decisions utilize external resources, often with considerable time commitment. Money and Crotts (2003) identified various external information sources including (1) personal (e.g., WOM advice from friends and relatives), (2) marketer-dominated (e.g., advertisements in print and electronic media), (3) neutral (e.g., third-party sources such as travel agents), and (4) experiential sources (e.g., direct contact with retailers).

WOM has been long recognized as one of the important external information sources for travel planning (Gretzel, Yoo, \& Purifoy, 2007). WOM communication refers to interpersonal communication among consumers concerning their personal experiences with a firm or a product (Richins, 1983). Previous studies illustrate the significance of WOM for consumer purchase decisions, especially within a service context (Brown \& Reingen, 1987; Engel et al., 1993). Because service products are intangible and cannot be easily described, consumers tend to rely on WOM from an experienced source to lower perceived risk and uncertainty (Bansal \& Voyer, 2000). Brown and Reingen (1987) noted that WOM contributors do not profit monetarily regardless of the receiver's ultimate action of purchasing the good or service. Thus, WOM advice is perceived as a trustworthy and unbiased information source. It is argued that WOM can be transmitted beyond face-to-face interaction and can be communicated through electronic modes (Buttle, 1998).

Recent studies on travel information searches have witnessed a tremendous growth of interest in digital information from the Internet and its impact on travel planning (Crotts, Mason, \& Davis, 2009; Gretzel et al., 2007; Mack, Blose, \& Pan, 2005; Pan, MacLaurin, \& Crotts, 2007; Wang \& Fesenmaier; 2004). According to the US Travel Association, over 150 million US adults used the Internet for their 2009 business and leisure travel planning (US Travel Association, 2010). The Internet is a massive source of information for both travelers and commerce. Tourists have boundless information gathering opportunities on destinations, attractions, and pricing. Werthner and Ricci (2004) recognized the tourism industry as the leading business-tobusiness application on the Internet. Internet marketing researchers focused their early attention towards online consumer behavior and advertising (Hoffman \& Novak, 1996) with more recent attention on customer relations and the selling of products (Wang \& Fesenmaier, 2004).

With the advent of Web 2.0 technology, the Internet offers new ways for tourists to learn about tourism products and services directly from other consumers. Jang (2005) described the Internet as an alternate communication channel, where tourists can post blogs, write reviews, respond to comments and feedback, and participate in communities. Litvin et al. (2008) suggested Web 2.0-enabled social media is the polar opposite of traditional forms of media and marketing since content is generated by the consumer rather than by the marketer. In the digital era, the consumer-generated content in various forms of social media websites serves as an electronic WOM while likely influencing travelers' experiences (Litvin et al., 2008; Yoo \& Gretzel, 2011).

\section{New Form of WOM, New Source of Information}

WOM exchange was traditionally limited between acquaintances within certain geographical distances. Nowadays, consumers are able to access electronic word of mouth (eWOM) from friends and relatives, even strangers worldwide (Pan et al., 2007). In an online context, WOM communication occurs when consumers create their own information on the Internet to share their experiences and views about products they have purchased (Park, Lee, \& Han, 2007). Bruyn and Lilien (2008) summarized the difference between WOM and its 
online counterpart. First, online WOM requires no face to face interaction. Senders and recipients communicate through electronic media and are usually voluntary. That is, the sender does not have an obligation to distribute information. Likewise, the recipient does not solicit the information and may or may not pay attention to the information.

Given that WOM has been recognized as an extremely influential source of consumer information, the Internet's facilitation of this communication draws attention of tourism academics and practitioners. Considerable research has been directed at better understanding the motivation to spread eWOM. Wang and Fesenmaier (2004), based on a social psychological approach, explained why members spread WOM on travel 2.0 websites. They concluded that consumers are driven by the three incentives of instrumental, efficacy, and expectancy. Empirical studies also found individual differences in eWOM communication, indicating that personal characteristics such as age, gender, income level, race, and personalities are influencing factors of distributing eWOM (Yoo \& Gretzel, 2011). Moreover, the impact of eWOM on travel decision making has also been studied. For example, Gretzel et al. (2007) explored the impact of online travel reviews on consumers. Findings revealed looking at other consumer comments/ materials on online travel review sites was the most frequently utilized source of information. The credibility of the person writing the review tends to be judged by his/her previous travel experience and the level of similarity between his/her profile and that of the reader.

Online reviews are one of the most important forms of travel-related eWOM (Yoo \& Gretzel, 2011). Park et al. (2007) described an online review as new information presented from the perspective of consumers who have purchased and used the product, based on their experience, evaluation, and opinions. The reason why consumers post reviews online varies from person to person (Walsh, Gwinner, \& Seanson, 2004). Some people are motivated by the desire for social interaction, concern about other consumers, or the possibility of enhancing social status (Hennig-Thurau, Gwinner, Walsh, \& Gremler, 2004). Others may simply want to vent their frustration about negative experiences (Shea, Enghagen, \& Khullar, 2004).
Online consumer reviews not only provide other consumers with information from real users of products and services but also act as WOM recommendations (Park et al., 2007). Exposure to online consumer reviews increases the consumers' intention to purchase a product and maximize the likelihood that consumers will buy a recommended product (Park et al., 2007; Senecal \& Nantel, 2004). Senecal and Nantel (2004) note that product recommendations from other consumers are even more important to prospective purchasers when an experiential product (e.g., intangible services such as tourism) is of concern as opposed to a tangible product. Generally, travelers perceive online reviews are more likely to provide reliable, up to date, and enjoyable information than travel service providers. It should be noted that frequent travelers particularly consider peer reviews as superior to other information sources and are more likely to be influenced (Gretzel et al., 2007).

Tourism literature has historically focused on traditional travelers. Research on RV travelers is quite limited. Early research studied campers' preference for public, private, or state owned campgrounds (Hammitt \& Strohmeir, 1983). Ronkainen and Woodside (1984) focused on a campground's tourism strategy and market share while Arimond and Lethlean (1996) conducted a profit center analysis within private campgrounds. Connelly (1987) identified solitude, nature, and facility characteristics as three factors critical to camper satisfaction. Ouellette and Wood (1998) found consumer choice is related to previous experiences of satisfactory outcomes. Facility upkeep was a direct critique of management practices. McFarlane (2004) studied the behavioral, cognitive, and psychological attachment of recreation specialization to the choice of recreation settings and site selection.

Information search behavior and decision making of RV travelers are often overlooked. The electronic information sources such as online community, discussion forum, consumer reviews, and blogs are emerging for the RV travelers where RV travelers share their campground experience and interact with others. The study aims to fill the literature gap of understanding the RV visitors' experience by analyzing online reviews posted on campground websites. Several research questions will be addressed: (1) What did RV visitors' experience at 
a campground site? (2) What campground attributes affected the RV visitor experience? (3) Were RV visitors satisfied or dissatisfied with the campground attributes? Why?

\section{Research Methodology}

The present study examined RV travelers' camping experiences by analyzing online campground review website postings. A Google search was conducted to determine how many websites were available for online postings of campground experiences in the US. A subcriterion for the website selection process was applied based upon the flexibility of deciphering online postings by state and/ or by region. The search revealed two major online review websites: www.campgroundreport.com and www.rvparkreviews.com. The first one was selected for data analysis owing to its user-friendly data structure and richer content of RV travelers' camping experience. In addition, the southeast region was randomly selected from this website with text from all eight southeastern states analyzed. Table 1 notes the states and respective number of postings transferred.

The present study followed a qualitative research design. Owing to the complexity of analyzing text data, a manual content analysis of the online postings was performed instead of utilizing software for the present study. The decision was made based on the fact that campgrounds have multiple features and amenities, including the RV site, bath houses, clubhouses, and recreational activities. Language on the postings may be used interchangeably to describe two different campground features or amenities. Software may not be able to distinguish such difference. For example, low water pressure at

Table 1

States and Number of Postings Transferred for Analysis

\begin{tabular}{lc}
\hline State & No. of Postings \\
\hline Florida & 35 \\
North Carolina & 27 \\
Georgia & 18 \\
Tennessee & 15 \\
Alabama & 11 \\
Louisiana & 10 \\
Kentucky & 9 \\
Mississippi & 5 \\
\hline
\end{tabular}

a campsite would likely have a more powerful impact on the RVer when compared to low water pressure at the shower or laundry facility in the campground bathhouse. Software will extract "low water pressure" but may fall short in the magnitude in which it was intended. Thus, the researcher followed a four-step procedure often noted as "thick description analysis." Denzin (1989, p. 83) described thick description analysis as establishing significance of an experience or sequence of events for the person in question. In thick description, the voices, feelings, actions, and meanings of interacting individuals are heard.

The unit of analysis determined for the present study was a 12-month period between June 2009 and June 2010 to depict a full year of experiences. The following steps were followed for data analysis. First, each post was transferred into a word document for analysis. A total of 130 posts were transferred. Second, the online postings were manually analyzed by key word or phrase frequency. Words commonly used in sentence construction, such as "the," "a," "and," "of," for example, were not counted. Table 2 depicts the most frequently used keywords and/or phrases.

Third, attempts were made to decode the underlying themes of the keywords. Two researchers independently reviewed the postings to identify themes, patterns, and topic areas. Themes from both researchers' lists were discussed and compared, ending with a comprehensive list of six major themes: campground attributes, campsite attributes, outdoor activities, surrounding area, campground policies, and staff. Next, the researchers reviewed the patterns evident within each theme. Measures were taken to ensure reliability and consistency of the text data analyzed. In particular, following Rust and Cooil (1994), interjudge reliability was tested for determining minimum acceptable levels of reliability for qualitative judgment, based on the proportion of agreement of the two judges. In this study, the interjudge reliability was based upon the proportion of total pairwise agreements between several judges viewing the same material, according to Kassarjain (1977). Consistency was determined by calculating the interjudge reliability percentage determined by the number of similar themes and topics as compared to the comprehensive list by both researchers. The 
Table 2

Most Frequently Used Keywords in Online

RV Travel Postings

\begin{tabular}{|c|c|}
\hline No. & Keyword \\
\hline 128 & site \\
\hline 77 & campground \\
\hline 44 & nice \\
\hline 32 & friendly \\
\hline 26 & beautiful \\
\hline 22 & staff \\
\hline 22 & water \\
\hline 15 & helpful \\
\hline 14 & electric \\
\hline 12 & quiet \\
\hline 12 & return \\
\hline 11 & pool \\
\hline 9 & kids \\
\hline 9 & fishing \\
\hline 8 & bathroom \\
\hline 8 & fix \\
\hline 8 & facilities \\
\hline 8 & grass \\
\hline 8 & laundry \\
\hline 8 & sewer \\
\hline 8 & WiFi \\
\hline 6 & paved \\
\hline 6 & picnic \\
\hline 6 & service \\
\hline 5 & access \\
\hline 5 & beach \\
\hline 5 & management \\
\hline 5 & negative \\
\hline 5 & privacy \\
\hline 5 & problems \\
\hline 5 & reservations \\
\hline 5 & unlevel \\
\hline 4 & amenities \\
\hline 4 & conveniences \\
\hline 4 & length \\
\hline 4 & playground \\
\hline 4 & restaurants \\
\hline 4 & rules \\
\hline 4 & stores \\
\hline 4 & trails \\
\hline
\end{tabular}

composite score was 0.857. Kassarjain (1977) declared a composite score above 0.85 is acceptable and indicates an appropriate liability. A total of 21 general topics resulted based upon the interjudge reliability. Table 3 references the themes, topics, and examples of postings.

\section{Findings and Discussions}

\section{Campground Attributes}

Campground attributes received significant attention in the reviewed postings. The most reported topics were on-site convenience stores, kid-friendly and pet-friendly environments, property upkeep, ease of access, and overall value. What the campground has to offer appears to influence an RV traveler's experience and/or satisfaction. On-site convenience stores, often referred to as camp stores in the RV industry, provide a wide assortment of products related to camping and RVing needs. Most RV travelers stock their RVs with essentials prior to and during their trip. As assumed with any travel, there may be items that were either overlooked, deemed unnecessary during packing, or inaccessible at the time of departure. As one RV traveler indicated: "I used the camp store a lot more than expected." Items such as cooking staples, toiletries, firewood, RV repair products, ice, and additional snacks were specifically noted as purchases in on-site stores. Camp stores were also noted for their convenience. To put in perspective, setting up an RV at the designated campsite can be very time consuming. Set up often includes electrical, water, sewer, and cable connections in addition to leveling the RV. Thus, the convenience of an onsite camp store will free an RVer from disconnecting from their campsite should they long for an item commonly found at a camp store. Consequently, the convenience factor of camp stores may be more dramatically noticed by the RV traveler when one is not available, as depicted by one RV traveler: "Great local restaurants but not too many convenience stores nearby. Go prepared. No onsite camp store."

Kid- and pet-friendly related posts were also revealed in the postings. Amenities often found at campgrounds, attractive to families traveling with children, are playgrounds and pools. Playgrounds notoriously provide entertainment and activity for young RV travelers. Swimming pools, on the other hand, benefit all demographics. The RV lifestyle is also conducive to travelers with pets. In fact, traveling with pets is often the main reason to travel by RV. A common amenity and/or feature attractive and subsequently utilized by RV pets are designated pet runs or fenced in areas. The following traveler references both kid-friendly and petfriendly campground attributes collectively, providing credence to the noted attributes. "The campground is pet-friendly with a pet exercise area, motorcycle ramp for taking your bike on and 
Table 3

Summary of Themes, Topics, and Text Postings

\begin{tabular}{|c|c|c|c|}
\hline $\begin{array}{c}\text { Campground } \\
\text { attributes }\end{array}$ & $\begin{array}{l}\text { Kid-friendly; } \\
\text { Pet-friendly; } \\
\text { Property upkeep; } \\
\text { Ease of access; } \\
\text { Overall value }\end{array}$ & $\begin{array}{l}\text { Huge camp store open } 7 \mathrm{am}-10 \mathrm{pm} . \\
\text { The pool was nice. } \\
\text { The restaurant was delicious. } \\
\text { The pool was crystal clear, bathrooms immaculate. } \\
\text { Price of an overnight stay is commensurate with the } \\
\text { amenities. } \\
\text { Easy access on and off highway. } \\
\text { They had their brand new club house decorated } \\
\text { very nicely. } \\
\text { Nice pet run. Fenced in with benches and agility } \\
\text { stations. } \\
\text { Great playground. } \\
\text { Laundry facilities were great. }\end{array}$ & $\begin{array}{l}\text { When they fixed the power, it was } \\
\text { turned off for } 2 \text { days with no } \\
\text { reduction in the rate. } \\
\text { Information says free WiFi. There } \\
\text { was a charge. } \\
\text { Clubhouse is seldom open. }\end{array}$ \\
\hline $\begin{array}{l}\text { Outdoor } \\
\text { activities }\end{array}$ & $\begin{array}{l}\text { Pool policies; } \\
\text { Fishing; Fitness; } \\
\text { Entertainment }\end{array}$ & $\begin{array}{l}\text { We found that we truly enjoyed the amenities } \\
\text { which included the beach and also the fishing } \\
\text { pier. } \\
\text { The bonfire in the evening was a great addition to } \\
\text { the country band. } \\
\text { Huge pool. Nice adult only hot tub. }\end{array}$ & The workout room was not open. \\
\hline $\begin{array}{l}\text { Surrounding } \\
\text { area }\end{array}$ & $\begin{array}{l}\text { Nearby restaurants; } \\
\text { Nearby conve- } \\
\text { nience stores; } \\
\text { Overall beauty }\end{array}$ & $\begin{array}{l}\text { There are numerous dining establishments nearby } \\
\text { Close to many great FL State Parks. } \\
\text { The beautiful surrounding mountains. } \\
\text { Campground more than made up for the any } \\
\text { maintenance issues. }\end{array}$ & Convenience store 5 miles away. \\
\hline
\end{tabular}

off your truck/trailer, a playground for the kiddies, arcade with video games, pool tables and access to nearby hiking trails and grocery stores."

The upkeep and appearance of campground amenities apparently impact the overall experience of RV travelers. RV travelers did not hesitate to critique the present condition of the campground amenities. One traveler offered the following reference to a lounge, the Internet service, and a maintenance issue, substantiating areas of significance. "The lounge is big and WiFi was very helpful. The bathrooms were clean. There also was a large kitchen.
The laundry had working washers and dryers. The only problem was the automatic door; the spring needs to be fixed." Another traveler posted: "Our campsite was nice but during our 4 week stay almost everything in the park was broken down at one time or another. The park was willing to fix the problems but for the price it was more inconvenient than it was worth."

Campgrounds are often nestled on acreage that may not be visible from an exterior roadway. Signage to the campground entrance is important not only for directional access but also for 
maneuverability. Many of today's rigs are large. Minimizing wrong turns is assumedly preferred. The following contrasting views substantiate ease of access preferences while reinforcing the importance of good directional signs for the arriving guest. "There were big signs and arrows directing us right to the park. Thank you. It made our arrival a little easier." And in contrast: "We arrived at night, the entrance was dark with no street lights, and if there was a sign, we didn't see it. Tough way to start our stay."

Lastly, RV travelers provided their insight as to the overall value of their campground selection. Expectations met during the RV traveler's stay are an important variable when assessing value received at their campground of choice. As one traveler posted: "It is easy to get to from I-10 and just as easy to get out of. There are numerous dining establishments nearby and the price of an overnight stay is commensurate with the amenities. We enjoyed both nights we spent here."

\section{Campsite Attributes}

Today's recreational vehicle has incurred tremendous changes over the past 100 years, in length, in width, and in offerings. Campground layouts, for example, have often been reconfigured into larger sites to accommodate the increased length, width, and demands of today's RV. Electrical power outlets have been upgraded to accommodate $100 \mathrm{amps}$ of service while adequate water pressure has been increased to substantiate the demands of today's RVs. Sewer outlets have been installed at campsites for convenience and cable television hook ups have been provided to match the entertainment features in today's RV. Campsite attributes received significant attention in the reviewed postings. The most reported topics were hook ups, layout, features, and value.

Multiple procedures are performed upon an RV traveler's arrival at a designated campsite. Prior to positioning a recreational vehicle, the placement of campsite amenities is noted by the RVer and is often times factored into the ultimate positioning of the recreational vehicle on that particular site. For example, the location of water, electrical, and sewer are critical for easy hook up. Expectations by the RV traveler would be that all such features are in good working order and are located for convenience of use. One RV traveler offered insight when location of hook ups were not easily accessible, resulting in dissatisfaction upon arrival: "Our site itself was difficult to set up because the electric box was in the back left corner of the site, the sewer was up at the front left corner of the site (so far that we needed to go out and buy some additional hose), and the water spigot was at the front right side of the camper (but thankfully we had extra hose)."

Today's recreational vehicle has become increasingly larger over the years. Consequently, many RVers prefer and/or require a larger campsite for maneuverability. As one traveler posted, "Beautiful park with concrete streets and double wide level concrete sites." Additionally, a recreational vehicle has the ability to expand six feet when the slide-out rooms are extended. Distance between neighboring campsites, consequently, may be compromised when the expandable rooms are extended, resulting in decreased privacy. The following two posts critique campsite layouts, in particular, privacy. "The sites are coquina sand, in the middle of a lush tropical forest. Really natural and beautiful, huge sites." And another RV traveler posted: "The only drawback is that the spaces are a little close together, but you can reserve some of the better sites with more room."

The levelness of an assigned campsite was also noted as an influence to the RV travelers' campground experience. A key component in finalizing set up of the recreational vehicle is that of leveling the rig. Leveling is crucial for comfort while camping as well as the effective operation of appliances and gauges while at rest. A RV traveler offered a critique with regards to levelness: "The site was very unlevel. Some of the other sites near us had the same problems. We were on grass but the site next to us had a slab. It was sort of hit or miss. Nevertheless, once we got hooked up we had a nice time."

Entertainment systems in today's RVs have paralleled home systems, including satellite television service while parked and also while in motion. High-definition televisions are standard in most rigs today, often contributing to the expectation that cable service will be provided at the assigned campsite. Internet access is also desired, sometimes a necessity. The following posts reference features 
at a campsite. "Free WiFi connection was excellent and the cable choices were great." "The cable and WiFi is free and first rate. Highly recommended campground."

$\mathrm{RV}$ travelers, as previously mentioned, assess the overall value of a campground. RV travelers also assess value as related to campsite offerings. As one RVer referenced: "No problems for our big rig and everything is included in their price. Managers are very friendly and helpful. We will be back often on our trips south." Another referenced the importance of an all-inclusive pricing package: "It's nice when all is included, no hidden extra fees for cable, Internet, etc. Will stay again."

\section{Outdoor Activities}

The RV lifestyle attracts all demographics. Addressing the diverse needs of travel parties creates opportunities and challenges for the respective campground. For example, enforcement of rules and age restrictions at on-site swimming pools received conflicting assessments in the postings. One RV traveler expressed satisfaction with the swimming pool rules and regulations at the respective campground. "It was great to see a designated 'adult only' swim time for those of us who would prefer not to compete with active children." On the contrary, however, a not so pleasant experience was referenced by another RV traveler at his/her respective campground: "Unfortunately, staff wasn't readily available to enforce the adult only policy, leaving an uncomfortable exchange between adults and parents of children. It's amazing why the signage alone could not deter confrontation."

Fishing and fitness opportunities were also noted in the postings. Ponds located on campground properties are attractive to RVers for their fishing, for their aesthetics, and for their picnic backdrops. The following provides two positive reviews of onsite ponds. "Has a beautiful lake for swimming and fishing." "The fishing was great for my husband and just relaxing was great for me." Campgrounds with walking trails, biking areas, basketball courts, volleyball courts, and indoor gym facilities on-site or nearby drew attention to those seeking specific outdoor activities during their stay. "Walking/riding trails at entrance of campground. Lots of geocaching in the area." "Come to this park if you want outdoor fitness. They have a trail nearby for bikes, walking, and running."

A growing trend in campground offerings is that of outdoor entertainment. Campgrounds commonly will offer movies either indoor, via a lounge television, or outside on a suspended drop cloth or erected screen. More recent offerings have included live singers and bands for the campground guests. Providing an all inclusive experience appears to be the focus and trend of campgrounds. Two such postings depict on-site entertainment experiences. "The bonfire in the evening was a great addition to the country band." "The outdoor movies were fun. The selection was more for kids but I think they had other movies available if no kids showed up."

\section{Surrounding Area}

The fourth theme depicted was directed towards the RVers' interest in the surrounding area. The most reported topics included nearby restaurants, convenience stores, and overall beauty. The RV lifestyle allows travelers to cook at their site and/or in their rig. Nearby restaurants and convenience stores are added benefits even when most comforts of home can be found in a recreational vehicle. One RV traveler documented the importance and proximity of such venues in relation to their campground: "The campground is located just across the Interstate from all the restaurants and shopping. There are also various convenience stores in the general area."

RV travelers may select a campground as a stop along their travel route or as their destination. It would be assumed that RV travelers, assuming their stay was long enough, will venture out to the surrounding area to discover the vistas and/or area attractions. One RV traveler appears to have had some disappointment at the campground but was tempered by the surrounding area: "The beauty of the surrounding mountains and campground more than made up for any maintenance issues we had."

\section{Campground Policies}

Like any business, campgrounds have policies covering various facets of the campground operation. The most documented topics included refunds, quiet parks, and safety. Refunds are usually only an issue when there is a need to request one. Thus, it 
would be assumed that more negative posts than positive posts would be revealed. The following two posts document refund policies: "No refunds" and "Be careful making reservations here as they make no refunds for any reason." Such experiences and related policies appear inflexible, especially if an emergency alters a traveler's itinerary. More than likely, however, a no-refund policy has been established for all non-emergency-related cancellations. History often times dictates why strict policies are established. Clarity should be sought prior to confirming a reservation at any campground, just as the traditional traveler would do in a hotel. There certainly are possible exceptions to the rule; however, one must take personal responsibility in clarity of refund policies prior to commitment of stay.

Regarding quiet hours, some campgrounds are generally quieter than others. As with any property, it is possible that noise from other patrons and guests can interfere with a guest's stay and subsequent enjoyment. Thus, the enforcement of quiet hour policies is important, not only for those affected but for overall consideration of campground rules. As one traveler posted: "Campground staff immediately responded to the 2 am party that had no indication of slowing down or becoming quieter." And of course, with any situation, the reverse can be experienced. The following post referenced a completely opposite experience and would be a great promotion for those looking for a quiet environment while camping: "If you are looking for quiet, as we were, this is it."

Safety is a concern no matter where an RVer may choose to park. Appropriate lighting, gates, and designated personnel were common posts when referring to safety. As one traveler depicted, "I felt very comfortable during the evening and early morning hours. I noticed campground staff making themselves visible by traveling throughout the campground on a golf cart. I'm not sure if this continued all night, but I do know there was a sign at the office stating 24 hour security."

\section{Staffing}

The final theme depicted, but not of less importance, was staffing. Two major topics emerged with regards to personnel: service and friendliness. Service postings included initial communications during the reservation process, experiences upon arrival, and on-site encounters. The campground itself may very well be the destination for the traveler. The reservation process commonly includes the discussion of rates, an accurate description of on-site amenities, and specific site availability for the noted travel dates. All are important details discussed between the traveler and campground staff. As with any industry, negative experiences unfortunately occur. Consequently, such stories and experiences are openly shared: "Planned our vacation months in advance and called in March asking for a good site for July. We were given a small site next to a seasonal with a $30 \mathrm{ft}$ silver converted hauler next door. So close that our awning touched the side of his trailer." In another case, reliance on posted hours of operation was reflective not only on the staff but also on campground policies. As posted, "Lady who ran the camp store left 40 minutes before official closing time. Why post hours!" In contrast, however, services commonly not offered in traditional lodging settings can add a personalized level of service to the arriving traveler. For example, receiving an escort to the assigned site is a common service and one that is appreciated by many travelers: "Staff was super friendly and very helpful. Check in was great and fast. We were led to our site. We will absolutely stay here again."

\section{Conclusions and Implications}

The present study contributes to the literature and for the industry in several ways. The current study has provided empirical evidence identifying RV travelers' perspectives from recent campground experiences. Campground owners/operators can gain valuable insight as to the attributes of most importance for today's RV traveler. Braun (2002) recognized networks, knowledge, and relationships as crucial assets to business survival. Importantly, amenities not previously identified as significant may very well be a major influence and/or distinguishing factor that steers today's traveler to a respective campground. Amenities and attributes not listed in the current study should not be ignored or discounted. The RV industry and corresponding lifestyle have evolved over the years and will assumedly continue. Marketing efforts should focus on attributes significant to today's traveler. 
Campground owners/operators may also want to begin cataloging online postings and blog narratives specific to their property, which will identify patterns and trends of their guests' experiences and RV lifestyles to date. Campground owners/operators should immediately address negative notations in online postings, understanding that perceptions may ultimately influence their guests' experiences. For example, postings reflecting maintenance, cleanliness, or minor aesthetic improvements should be and can be addressed immediately. Postings regarding the need or request of upgraded amenities should be strongly considered, such as cable upgrades, WiFi offerings, and plantings for privacy between sites. Issues concerning major renovations such as wider streets, better lighting, and larger sites may be better positioned for future strategic planning efforts. Important to note, campgrounds of the past were often fields of land with few amenities and/or services. Campgrounds are evolving to become compatible to today's RV traveler with goals to attract, satisfy, and sustain their market share. Therefore, completed renovations should be broadcasted immediately in marketing literature, websites, and campaigns. Lastly, friendly and caring staff can overshadow unpleasant experiences. Reinforcing the importance of delivering outstanding guest services is highly recommended.

Interestingly, three postings could be classified as outliers with respect to frequency and reference yet have tremendous significance to the campground owner/operator; campground ratings, misleading ads, and loyalty programs. Campgrounds, like their traditional counterparts, acquire ratings from industry sources. Ratings commonly reflect amenities, cleanliness, and visual appeal. Interestingly, campground rating categories mirror themes and topics identified in the current study. As an example, one RV traveler disagreed with a particular campground rating once arriving at the respective campground. A published rating of a campground may contribute to a RV traveler's prearrival expectation, potentially influencing their satisfaction and substantiating a negative review of the campground. Ratings, therefore, could negatively impact a campground's reputation, warranted or not, based upon the RV traveler's perception.

Misleading RV guests with false advertising prior to arrival, whether intentional or not, may potentially lead to unsatisfactory experiences. Campground owners/operators should make a concerted effort to synchronize marketing literature to accurately represent the present condition of the campground. Today's technology affords campground owners/operators the ability to update websites as needed.

Lastly, loyalty programs for return visits had few references yet may potentially impact a campground's future market share. Such programs are rare in the campground industry but common in other sectors of the travel and tourism industry. Loyalty programs should be explored to increase repeat business.

The RV traveler is a significant beneficiary of the current study. Word of mouth is powerful. RVers have the opportunity to read experiences of those who have traveled before them. Important to note is that most postings are short, providing only a snapshot of the entire experience at the campground. Therefore, it is suggested that RV travelers temper the negative connotation of posts and absorb such comments as information only. A posting, for example, may refer to poor or no $\mathrm{WiFi}$ reception or low water pressure. A simple question to the campground owners/operators during the reservation inquiry, referencing such issue, would document if it is an ongoing issue or an isolated incident. Likewise, campground owners/operators should voluntarily address such noted concerns. Communication is key.

\section{Limitations and Future Research Directions}

There were limitations to the present study. First, the validity of the postings rely on the honesty and accuracy of the postings. Forums represent personal opinions of personal experiences. Perception bias, therefore, may play a role in the posting. Some researchers argue that blogs are a form of individualistic self-expression rather than a form of documenting current external events (Pan et al., 2007). Second, the validity of the postings relies on the authenticity of the RV traveler who is posting a review. It may be argued that travelers posting $\mathrm{RV}$ campground experiences may or may not have experienced the posted event. Zehrer, Crotts, and Magnini (2011) analyzed blog narratives for potential deception. Potential deception, in this particular 
study, was identified as narratives lacking first person references. Controlling for such potential deception did not significantly impact their findings. The present study did not analyze postings for deception, thus a noted limitation. Third, the postings reviewed within the region were not randomly selected. Every posting during the defined time frame was analyzed. Fourth, the sample size was small. A larger sample from multiple websites would be suggested for future studies. Lastly, content analysis is subjective, providing potential bias on the part of the researchers.

Future research opportunities are plentiful. The present study was an initial effort to explore RV travelers' campground experiences as showcased in online forums. Return intentions of the reviewed travelers' postings were not explored. Future studies could identify variables influencing RV travelers' satisfaction and return intention of their chosen campground. The present study also identified outlier postings. Future studies could expand this discovery by comparing campground ratings respective to consumer ratings. Loyalty programs received little attention in the present study's reviewed postings yet could be of significance to both the industry and the consumer. A future study should explore the feasibility of loyalty programs. Lastly, future research could expand all future research agendas internationally as RVing is a global lifestyle.

\section{References}

Arimond, G., \& Lethlean, S. (1996). Profit center analysis within private campgrounds. Journal of Travel Research, 34(4), 52-58.

Bansal, H., \& Voyer, P. (2000). Word of mouth processes within a service purchase decision context. Journal of Service Research, 3(2), 166-177.

Bieger, T., \& Laesser, C. (2004). Information sources for travel decisions: Toward a source process model. Journal of Travel Research, 42(4), 357-371.

Braun, P. (2002). Networking tourism SMEs: E-commerce and e-marketing issues in regional Australia. Information Technology and Tourism, 5(1), 13-23.

Brown, J., \& Reingen, J. (1987). Social ties and word-ofmouth referral behavior. Journal of Consumer Research, 14(3), 350-362.

Bruyn, A. D., \& Lilien, G. L. (2008). A multi-stage model of word-of-mouth influence through viral marketing. International Journal of Research in Marketing, 25(3), 151-163.
Buttle, F. A. (1998). Word of mouth: Understanding and managing referral marketing. Journal of Strategic Marketing, 6(3), 241-254.

Cha, S., McCleary, K., \& Uysal, M. (1995). Travel motivations of Japanese overseas travelers: A factor-cluster segmentation approach. Journal of Travel Research, 34(2), 33-39.

Connelly, N. A. (1987). Critical factors and their threshold for camper satisfaction at two campgrounds. Journal of Leisure Research, 19(3), 159-173.

Correia, A. (2002). How do tourists choose? Tourism, 50(1), $21-29$

Crompton, J. L., \& Ankomah, P. K. (1993). Choice set propositions in destination decisions. Annals of Tourism Research, 20(3), 461-476.

Crotts, J., Mason, P., \& Davis, B. (2009). Measuring guest satisfaction and competitive position in the hospitality and tourism industry. Journal of Travel Research, 48(2), $139-151$.

Denzin, N.K. (1989). Interpretive interactionism. Newbury Park, CA: Sage.

Engel, J. F., Blackwell, R. D., \& Miniard, P. W. (1993). Consumer behavior (8th ed.). Chicago, IL: Dryden.

Fodness, D., \& Murray, B. (1997). Tourist information search. Annals of Tourism Research, 24(3), 503-523.

Fodness, D., \& Murray, B. (1999). A model of tourist information search behavior. Journal of Travel Research, $37(3), 220-230$

Gretzel, U., Yoo, K. H., \& Purifoy, M. (2007). Online travel review study: Role and impact of online travel reviews. Laboratory for Intelligent Systems in Tourism, Texas A\&M University. Retrieved from www.tripadvisor.com/ pdfs/OnlineTravelReviewReport.pdf

Gursoy, D., \& McCleary, K.W. (2004). An integrative model of tourists' information search behavior. Annals of Tourism Research, 31(2), 353-373.

Hammitt, W. E., \& Strohmeier, C. S. (1983). The likelihood of public campers to use nearby private campgrounds. Journal of Travel Research, 22(1), 15-17.

Hennig-Thurau, T., Gwinner, K., Walsh, G., \& Gremler, D. (2004) Electronic word of mouth via consumer-opinion platforms: What motivates consumers to articulate themselves on the Internet? Journal of Interactive Marketing, 18(1), 38-52.

Hoffman, D. L., \& Novak, T. P. (1996). Marketing in hypermedia computer-mediated environments: Conceptual foundations. Journal of Marketing, 60(3), 50-68.

Jang, S. C. (2005). The past, present, and future research of online information search. Journal of Travel and Tourism Marketing, 17(2), 41-47.

Kassarjain, H. (1977). Content analysis in consumer behavior. Journal of Consumer Research, 4(1), 8-18.

Laing, J. H., \& Crouch, I. J. (2009). Exploring the role of the media in shaping motivations behind frontier travel experiences. Tourism Analysis, 14(2), 187-198.

Lee, M., \& Cunningham, L. (2001). A cost/benefit approach to understanding service loyalty. Journal of Service Marketing, 15(2), 113-130. 
Litvin, S. W., Goldsmith, R. E., \& Pan, B. (2008). Electronic word-of-mouth in hospitality and tourism management. Tourism Management, 29(3), 458-468.

Mack, R., Blose, J., \& Pan, B. (2005). Believe it or not: Credibility of blogs in tourism. Journal of Vacation Marketing, 14(2), 133-144.

McCleary, K., \& Whitney, D. (1994). Projecting Western consumer attitudes toward travel to six Eastern European countries. Journal of International Consumer Marketing, 6, 239-256.

McFarlane, B. L. (2004). Recreation specialization and site choice among vehicle-based campers. Leisure Sciences, 26(3), 309-322.

Money, R. B., \& Crotts, J. C. (2003). The effect of uncertainty avoidance on information search, planning, and purchases of international travel vacations. Tourism Management, 24(2), 191-202.

O'Brien, S. (n.d.). Baby boomers create RV travel boom: Why baby boomers are increasing $R V$ sales. Retrieved from http://seniorliving.about.com/od/travelsmart/a/ rvtravelgrowth.htm

O'Connor, P. (2008). User-generated content and travel: A case study on TripAdvisor.com. In P. O'Connor, W. Höpken, \& U. Gretzel (Eds.), Information and communication technologies in tourism 2008 (pp. 47-58). Vienna, Austria: Springer Verlag.

Ouellette, J., \& Wood, W. (1998). Habit and intention in everyday life: The multiple processes by which past behavior predicts future behavior. Psychological Bulletin, 124(1), 54-74.

Pan, B., MacLaurin, T., \& Crotts, J. C. (2007). Travel blogs and the implications for destination marketing. Journal of Travel Research, 46(1), 35-45.

Park, D. H., Lee, J., \& Han, I. (2007). The effect of on-line consumer reviews on consumer purchase intention: The moderating role of involvement. International Journal of Electronic Commerce, 11(4), 125-148.

Ponting, J. (2009). Projecting paradise: The surf media and the hermeneutic circle in surfing tourism. Tourism Analysis, 14 (92), 175-185.

Richins, M. L. (1983). Negative word-of-mouth by dissatisfied consumers: A pilot study. Journal of Marketing, 47(1), 68-78.
Ronkainen, I. A., \& Woodside, A. G. (1984). Tourism strategy: A campground case example. Journal of Travel Research, 23(2), 32-35.

Rust, R. T., \& Cooil B. (1994). Reliability measures for qualitative data: Theory and Implications. Journal of Marketing Research, 31(1), 1-14.

Senecal, S., \& Nantel, J. (2004). The influence of online product recommendations on consumers' online choices. Journal of Retailing, 80(2), 159-169.

Shea, L., Enghagen, L., \& Khullar, A. (2004). Internet diffusion of an e-complaint. Journal of Travel and Tourism Marketing, 17(2/3), 145-165.

Shoemaker, S. (1994). Segmenting the US travel market according to benefits realized. Journal of Travel Research, 32(3), 8-21.

U.S. Travel Association. (2010). Executive summariesTravel use of the internet (2010 Ed.). Washington, DC: Author.

Vogt, C., \& Fesenmaier, D. (1998). Expanding the functional information search. Annals of Tourism Research, 25(3), 551-578.

Walsh, G., Gwinner, K. P., \& Seanson, S. R. (2004) What makes mavens tick? Exploring the motives of market mavens initiation of information diffusion. Journal of Consumer Marketing, 21(2), 109-122.

Wang, Y., \& Fesenmaier, D. (2004). Modeling participation in an online travel community. Journal of Travel Research, 42(3), 261-270.

Wang, Y., \& Russo, S. M. (2007). Conceptualizing and evaluating the functions of destination marketing systems. Journal of Vacation Marketing, 13(3), 187-203.

Werthner, H., \& Ricci, F. (2004). E-commerce and tourism. Communications of the ACM, 47(12), 101-105.

Xiang, Z., \& Gretzel, U. (2010). Role of social media in online travel information search. Tourism Management, 31(2), 179-188.

Yoo, K. H., \& Gretzel, U. (2011). Influence of personality on travel-related consumer-generated media creation. Computers in Human Behavior, 27(2), 609-621.

Zehrer, A., Crotts, J., \& Magnini, V. (2011). The perceived usefulness of blog postings: An extension of the expectancy-disconfirmation paradigm. Tourism Management, 32(1), 106-113. 